\title{
Notes on the Narratological Approach to Board Games
}

\author{
KOME - An International Journal of Pure \\ Communication Inquiry \\ Volume 4 Issue 2, p. 74-81. \\ (C) The Author(s) 2016 \\ Reprints and Permission: \\ kome@komejournal.com \\ Published by the Hungarian Communication \\ Studies Association \\ DOI: 10.17646/KOME.2016.26
}

\section{Mattia Thibault}

University of Turin, Interdepartmental Centre of Research on Communication, Italy

\begin{abstract}
Nowadays game studies are in the foreground of cultural and communication debates. Even if video games are strongly studied in semiotics, play is a wide field of study with many areas still unexplored. The area that this paper aims to explore concerns board games and it focuses on the relationship between game and narration and the role of a game's intertextual dimension from a semiotic point of view.

Semiotic tools that have been used include the Greimasian narrative sequence (a structuralist point of view that fits very well with the rigid, explicit grammaticalization of board games) and Génette's narratology, unavoidable for every reflection on intertextuality. Last, but not least, cultural semiotics, based on Jurij Lotman's works, offers a valuable asset for understanding the enveloping and organic structure that surrounds games.

The research proceeds to focus on some case studies of three ancient board games - chess, backgammon, and mancalas - underlining their common traits and differences. The paper shows that the structure of board games is very similar to the structure of the Greimasian narrative sequence, but they rather form a hybrid narration in which the player has a primary importance. Moreover, we see that games constantly retrieve sense from different kinds of other texts depending on the culture and society in which the game is played.

The aim of this research is not to propound a complete theory, but rather to indicate a possible path to follow, between many, that could be a valuable resource in the exploration and the understanding of play.
\end{abstract}

Keywords: Semiotics, Game, Narrative, Intertextuality.

\section{Introduction}

"Play can't be denied" stated Huizinga. Play is an activity that precedes culture, that even precedes man. Animals play: it is even necessary for their survival (Bateson 1956). Play is a major feature of human existence, essential for the childish learning and shaping many aspects of culture (Huizinga 1939). "Man is only fully a human being when he plays," stated Friedrich Schiller in his Letters upon the Aesthetic Education of Man (1794). Nowadays, the 
phenomenon of gamification - the introduction of elements proper of play in unrelated areas is more and more increasing. The Homo Ludens described by Huizinga (1939) is now becoming a Homo Ludicos (Ortoleva 2012): a real play-obsessed. Play is no longer only a fundamental aspect of culture, but it is becoming the main one.

Speaking about play in general, anyway, is very difficult. Play has many forms, and it would be impossible, here, to develop an analysis on the whole of its practices. It could be useful, therefore, to concentrate on games.

In the next chapters, we will approach these games in a semiotic way in an attempt to understand their relationship with narration and intertextuality. The objective of this paper is to analyze the functioning of board games and the elements that compose them in a structural and systematical way, investigating their texture and studying the way they characterize themselves toward other kinds of texts.

A final note: while analyzing games, it is always important to point out what is the object of our study. A first definition and circumscription of game is needed in order to start the analysis. There is a small amount of semiotic analysis of video games, for example, that apply semiotic tools to the practice of play. Those analyses prove only that playing is an action and so it could be susceptible to be narrated. What we want to do is extremely different. In this paper, we want to analyze what happens while a player is playing, during his fruition of the game. Our aim is neither to analyze what it means "to play" nor to determine the characteristics of a "game played," but rather to study what it means to be "playing games."

\section{Methodology}

No analysis of games could be done without reviewing the existing literature on play and games. On the one hand, Huizinga's work (Huizinga 1939) is still fundamental to understanding the primary importance of play for man and realizing how the play element is present in unexpected areas such as ritual and war. Bateson (1956), on the other hand, proposes some interesting considerations on the similarities between animal and human play from an ethological and psychological point of view. Roger Caillois built the first rigorous typology of play and tried to put some order to the eclectic and vague play-sphere (Caillois 1967). Last, but not least, we could mention Carse who has a valuable essay (Carse 1987) on the relationship between games and time. Even if all these analyses, with their strengths and weaknesses, are of primary importance in game studies, they all belong to other disciplines (sociology, ethology, psychology, anthropology, philosophy) opposed to the semiotic interpretation that we wish here to propose.

Actually, some semiotic works on games exist, even if mostly confined to video games and admittedly media-centric. ${ }^{1}$ Some of the concepts developed by this approach can be successfully applied to our analysis too, but most of them are devoted to a kind of text extremely different from ours and focus on topics such as virtual reality, the status of code inside a text, and the fact of games being potentially infinite: all features that are typical of digital games only.

The semiotic tools that will support our analysis are mainly from two different traditions. First is the greimaisan structuralist approach. The structure, says Lotman (1984), has to be considered a heuristic benefit and not an ontological property of the text. Indeed the canonical narrative schema proposed by Greimas (1966) is still a powerful and important instrument of analysis to investigate the elements in narration, and, in our case, even in games. The sequence "contract, action, sanction" together with his modalities (having-to-do, wanting-to-do,

\footnotetext{
${ }^{1}$ See, for example, Compagno and Coppock (2008). Ferri and alii (2013) or Mäyrä (2008).
} 
knowing-how-to-do, and being-able-to-do) will obviously pair with the actantial model, which requires a subject, an anti-subject, a value object, a sender, a receiver, helpers, and opponents.

On the other hand, the analysis of intertextual relationships of games will be based on Génette (1982). In particular, we will considerate an open form of intertextuality that concerns all kinds of texts and not only literature. For this purpose, it will be very important to bear in mind the concept of semiosphere, described by Jurij Lotman (Lotman 1984), which indicates the ensemble of all the signification processes of culture that coexist and mingle as a biological unity. $^{2}$

Finally, it could be important to remember the concept of "pleasure of the text," defined by Barthes (1973) as the spur that makes a reader read. In our case, of course, we can define it as "pleasure of the game." This new concept fits perfectly with the categories of play described by Caillois (1967). In "les jeux et les hommes" he individuates four different kinds of play based on the sensations felt while playing. These categories - alea (chance), mimicry (imitation), ilinix (dizziness) and agon (competition) - seem to be exactly what promote the pleasure of the game.

\section{Chess}

The first step to analyze the actantial roles in this board game is to identify the subject. In chess there are two sets of pieces, Black and White, but it is impossible to consider one of them as "the subject." The action, especially the performance, is not done by them. The player is the one that moves, acts. So is he the subject we are looking for? No, or better, not only him. It is true that he chooses a strategy and moves the pieces, but some of its competences are imposed by the rules. The player could actually make forbidden moves, but he chooses not to, out of respect for the game's restrictions. Accepting the terms of the game, the player becomes a part of a compound subject with hybrid modalities. The know-how-to-do is the player's own, but the wanting-to-do and the having-to-do are determined by the rules. The being-able-to is played half by the player (for example, being able to understand his opponent's strategy) and half by rules (for example, being able to move two pieces at the first turn). The player's pieces are, actually, the subject's helpers. This actantial role is compound, too. In this case, the rules set out what a piece is able-to-do (the kind of movement available) and sometimes what it has-todo (the king is forced to get out of check); the player will provide what the helper wants-to-do (moving or not and in which direction) and knows-how-to-do (for example how to avoid being taken). Reflective on these first two actantial roles, we find we have the anti-subject and the opponents. Everything we said about the subject and the helper is exactly the same for antisubject and opponents, only on the other side. The object of value is the victory, or better, the opponent's defeat by a checkmate, and it is completely provided by the rules. Regarding the contract, the role of sender is played by the agonistic nature of the game; the receiver, on the other hand, is the compound subject itself: both the "color" and the players are subjects to the sanction. Employing the canonical narrative schema and identifying the actantial roles in the game of chess, we can see that narration would not exist without the contribution of the player. In order to play, the player has to immerse himself in the narration, provide competencies, and fulfill modalities to mingle in the game and become a part of it.

In Juul (2005), games are defined as "half-real." Rules are the real half of the game - the other one is fictional and assists the player in understanding the game and playing it. Intertextual links and connections will be present in both halves, even if more clearly in the second one. In the game of chess, intertextual connections are strongly present. The military

\footnotetext{
${ }^{2}$ For a Lotmanian approach to games, see also Thibault (2015).
} 
metaphor is the driving force of the game, supported by the name of the pieces. Kings, queens, bishops, rooks, and knights today link us to the courtly medieval warfare and give sense to a game that without, it would just be the movement of some pieces of wood on a table. If the playing pieces had different names, the gameplay would be a rather different experience. If we take into consideration the diachronic evolution of the pieces, we will see that what we call the queen was once the vizir (and still is in many countries) and what we call the bishop was the elephant. In addition, in France, the bishop is the "fou" - the fool - and in Italy the "alfiere" is a soldier who brings the banner. Thus, what in Western Europe seemed a medieval contest was, in fact, the representation of a real battle of V century in Persia. The intertextual bond weaved centuries ago lasted until today, being transformed, traduced, and finally fixed into a "classical" model. The loss of one of the elements - in our case the elephant - in the cultural translation, brings the introduction of a new element that could be harmonic with the others and the receiving semiosphere. In some peculiar cases, maintaining the military metaphor, the pieces could be invested by quite different thematic roles. Various games of chess sets have been produced to reproduce ancient civilizations (as Romans vs. Egyptians) and even characters from films (The Lord of The Rings or Star Wars). The dimension of intertextuality in these last examples is even deeper, as we are not in presence of the retrieving of a thematic role, but of a complete character, or, at least, of his appearance.

The retrieving of thematic roles from other elements of the semiosphere causes chess to have meaning beyond the competition given by the rules. The pleasure of the game, therefore, doesn't come only from the agon, but also from the mimicry: the simulation of the battle on the chessboard. These two aspects coexist in the same game and are specific, respectively, of its real half and its fictional half. Therefore, half of the pleasure of the game is due to its intertextual connections.

\section{Backgammon}

The first ancestor of backgammon was created five millennia ago. The board game, born in Persia, had a remarkable diffusion and nowadays is one of the most played board games in the world. Thanks to its notoriety, there is no need to describe this game: we will begin the analysis of its narrative structure immediately.

The similarities with chess are many. The sender and the receiver are the same, as helpers and opponents. The first important difference concerns the performance, which is determined by a dice throw. Competencies and modalities - held by players and by rules - remain, but the being-able-to modality is provided by chance. Practically: for every move, the rules state that the subject has to move, the dice throw determines what kind of movement is "able-to-do," and the player makes the move thanks to his "know-how-to play." The subject, in this case, is treble and includes the uncontrollable and open component of alea, chance. The second important difference concerns the object of value. As it often happens in games of chance, sometimes backgammon is played for money. That way the object of value won't be only the victory, but the stakes include the points that will be converted into money. Money, however, is not a part of the play-sphere; it is a part of the "real" world. The object of value, therefore, won't be exclusively a part of the game, as in chess, but it becomes compound as the subject. Introducing gambling in backgammon makes the sanction more important for that part of the subject covered by the player because it has effects on the real life of the person himself.

Let's put the question of gambling on ice for now, and concentrate on the intertextual aspects of backgammon. Unlike chess, backgammon has only weak intertextual links. Neither the name of the game nor the name or shape of the pieces suggest anything else what they are in game. The only trace of links to other texts is the game's structure itself, that as the shape of an escape. 
The possibility to hit your opponent's checkers and capture them on the bar seems coherent with this metaphor. Even if not in backgammon, we can find some connections with "escape" in related games. In Turkish Tavla, for example, there is a strategy called "taking the doors" and in the Egyptian game Senet one of the more ancient ancestors of backgammon, some hieroglyph indicates words as "exit" and "adversity". Compared with chess, anyway, these intertextual links are quite mild, their function is basically to help the player to understand the meaning of the game thanks to a metaphor.

Concerning the pleasure of the game, agon is without any doubt one of the mechanism of gratification of the player, as for chess. Mimicry is not present, due to the lack of strong intertextual links, but the strongest spur to play is given by gambling - by a sanction that relevantly affects the player - and the presence of alea, of chance, that creates an atmosphere of pathos and wait, of continuous climaxes.

\section{Mancalas}

Mancalas are a group of African games (also present in Southern Asia and Central America) that are based on the common principle of sowing. The first examples of mancalas are dated by archaeologists between the 6th and 7th century AD in Ethiopia and Eritrea. Even if in Europe they are less known than chess and backgammon, they still have a great diffusion in many areas of the planet. I thought it could be important to analyze also this kind of games to have a various and multicultural point of view on board games.

In the family of mancalas exist dozens of games, with important differences between them about rules and ways of play. In this paper, we will not analyze deeply all kinds of mancalas or propose a typology of these games, but only investigate the characteristics in which we are more interested: their narrative structure and intertextual links. It could be important to remind that the word "mancala" came probably from the Arab naquala or the Swahili mankelah, both meaning "moving." The names of the different kinds of mancalas usually mean "table," "game," "sowing" and similar.

Mancalas are played on a board with various holes, or pits, positioned in one or more rows. In some cases, there are bigger holes called "stores" or "granaries" in which are gathered pieces no more in game or captured. Players put pieces, usually seeds or beans, in the holes, following a variable disposition, not fully fixed by the rules. Generally, each player owns the rows on his side. The game consists of a series of sowing in which a player select a hole with seeds that will be sown around the board. This selection is often limited to holes on the current player's side of the board, as well as holes with a certain minimum number of seeds. In some games when relay sowing, if the last seed during sowing lands in an occupied hole, all the contents of that hole, including the last sown seed, are immediately resown from the hole. The process usually will continue until sowing ends in an empty hole. It is also possible to capture seeds, in different manners according to the kind of game that's being played. The evaluation of the consequences of a sowing is the primary test of the ability of a player. The game ends when a player has no more legal moves, when he have no more seeds (in this case we have a famine) or when deadlock is reached. In some mancalas, as the Wari, the most widespread of these board games, there exists the "feed" rule: it is not possible to let your opponent in a famine, but it is necessary letting him keep some of his seeds or sharing with him some of yours. This is, in brief, the functioning of mancalas, even if all kinds of mancalas are different from each other.

The compound narrative structure that we have described for the other board games is broadly working also for mancalas, but with some, significant differences. First, the pieces, (the seeds) do not belong to one player, but they are continuously exchanged and captured. 
Thus, the seeds aren't only helpers or opponents of the subject, but also secondary value objects that have to be collected in order to gain the primary value object, the victory. On the other hand, seeds aren't simply a kind of scorekeeper, but they have a function and a usefulness in the game. Sowing make the seeds became helpers in order to gain other seeds and win the game. Of course, when the anti-subject is using them, they'll play the role of opponents. This double nature of either helpers/opponents and value objects could be summarized in the word "resources" borrowed by video games. Chance is not present in mancalas, even if, for a beginner, the sequences of multiple laps of sowing could seem unpredictable. It is up to the player's knowing-how-to-do the creation of a narrative program that allows him, thanks to an accurate calculation, to imagine the outcome of his move. This ever-changing narrative program - present also in the other board games - is what we call "strategy." The construction of a strategy, however, is influenced by the actions of the anti-subject, proposing his own narrative program that aims, of course, at his own victory.

The main theme of mancala is sowing, present in every level of the game. The words "granary," "famine" and "feed" are all linked with the sphere of agriculture, and so it's the disposition of the seeds in the holes. Using real seeds in the game opens a major intertextual relationship that involves every element of the game. It is impossible to say if it was the use of the seeds that shaped the game as an agricultural metaphor, but it cannot be excluded. The force of the meaning that permeates a seed in an agricultural society is enough to take with it a huge amount of sense connections that the game will inherit. Those connections will be so deep that in some case they can even reshape game's structure. The rules on "feeding" the opponent show precisely the strength of intertextual links in mancalas that come to a point where the victory conditions change in respect of the social rules of the real world. In this case, intertextuality affects both parts of the game strongly: the real one and the fictional one. Furthermore, the seeds aren't symbols, as the rook of chess, but they stand for themselves: they are objects proper to the real world, not to the play-sphere. The secondary object of value of mancalas, so, it is a compound object, like money for backgammon, even if, differently from money, the value of a seed is mainly due to a symbolic synecdoche. Thus, a positive or negative sanction to a player will not be determinant due to the value of the real object, but thanks to its symbolic strength.

As for chess, the pleasure of the game in mancalas is given by its elements of agon and mimicry. The imitation, in this case, is not the re-enactment of some heroic deed, but the introduction of strong connections with the exterior world and in particular with a fundamental area of the semiosphere of agricultural societies.

\section{Conclusions}

Concerning the narrative aspects of games, we observed that even if we could apply the canonical narrative schema of Greimas, games are not classical narrations, but rather are compound phenomena. The actantial role of the subject is played by multiple elements: rules, the ability and decisions of the player and, sometimes, chance. Also, some of the other actantial roles are characterized by the same compound nature. Video games scholars use the concept of "interactivity" as one of the primaries aspects of games, and they define video games as an Interactive Digital Narrative (Ferri, Haahr, Koenitz, \& Sezen 2013). This could work for video games, but, in my opinion, the relationship between game and player goes beyond the interactivity, and it is not limited to dialogue: it realizes a sharing and a compenetration of both. When the player accepts the rules and starts playing, he doesn't call into question the rules anymore; they became a part of him, of what he's doing. In the same way, he accepts the result of a dice throw and makes it a part of him in his new self: the subject of the play. This originates a compound narration that could have many different forms: it can include chance, it can require strategic thinking or mathematical competencies, it can sanction the subject with hybrid 
value objects that have different degrees of importance in the real world, and so on. These forms define not only the different kinds of games, but also the constant element stays the compound nature of the practice of playing a game. We shouldn't forget that in all the board games that we have analyzed two opposite players are present. The structure of these games is thus symmetrical: every subject is an anti-subject for the other; the opponents of one will be the helpers of the other. Every move made by a subject will influence the decisions of the other and interfere with his strategy. This relationship between subjects, and not between player and game, could appropriately be defined interactively.

Concerning the intertextual dimension of games, in all three board games, even if in different degrees, the intertextual connections have a primary importance, even if in some cases it's more evident than in others. For some games, intertextual links are part of the elements giving pleasure of the game, for others they are just a help to better understand the functioning of the rules and the objectives of the game. It is important to avoid the mistake of considering intertextuality as a characteristic that is applied to a game at a later time. The intertextual links actively participate in the creation of a game. A game is created within a semiosphere and is soaked through with the values and categories of its culture. Every intertextual link is a part of a system that can later be translated, retrieved, renewed, modified or strengthened. In some cases these connections could be deeper, in larger numbers or denser than in others and, depending on their nature, they can influence more or less the structure of the game.

Last, but not least, we had the occasion to do some considerations about the pleasure of the game. We saw that three out of four of the elements described by Caillois were present in the board games that we analyzed, as catalysts of the pleasure. More precisely we individuated agon, alea, and mimicry. Due to its physical nature, it is not surprising that ilinix has been excluded from this list: it fits within the definition of a board game with difficulty. In addition, we could notice that those elements were always present in the games in couples and that not every time one of them was predominant. Therefore, the work of Caillois, instead of drawing boundaries and typologies, has been very useful for outlining the mechanisms of gratification that we call "pleasure of the game."

We also have to point out the limits of this paper. We can't generalize the results of the analysis to all the kind of play, or even of game. There exists a large quantity of games and it would be scientifically unacceptable to assume that this analysis fits perfectly to every one of them without further researches. This analysis has to be considered as a cue and it aims to be an heuristic hint, not a typology or an ontological description. It is more about how a board game work, than about what a game is.

Nevertheless, in my opinion, this work could be useful for underlining two aspects of the game that, regardless of its contingent expressions, could be a starting point for further considerations on games and play.

The first aspect is the compound narrative shape that games assume. Beyond the different and controversial interpretations of the concept of narration - that divide video games scholars - applying the canonical narrative schema and the system of actantial roles at games, it's useful for understanding better their functioning. The aim it isn't the ontological description of games (are they narration or not?), but to shed some light on the way games work in connection with the player. I think that Lotman's lesson is capital, here. Structuralism is only a tool of investigation, a heuristic convenience, not a description of the object's ontology. Our analysis doesn't look for actantial roles with the only purpose to define a structure, but it aims at underlining the fusion (and confusion) that involves game and player in the act of playing. A fusion that goes beyond (and maybe precedes) the identification that could involve a reader. A fusion that spurs the player to become something else, to leave the real world and enter the play-sphere. I think that this, regardless of the methods used to cause this union - gambling, interpretation, intertextual connections, etc. - is a fundamental point for understanding what 
play means: not a simple interaction with rules or opponents, but the repositioning of an individual on another plane of reality, the reality of play, that needs him to transform into a hybrid, becoming something different.

The second aspect to underline is the essential belonging of a game to its semiosphere. A game could not be taken into consideration without the set of signification processes that surrounds it. It's not in order to make a philological reconstruction, but to analyze games as part of a system. Analyzing exhaustively the place that a game such as chess occupies in the semiosphere would be demanding work, and that is not our goal. What we tried to achieve is to show that in different games exist different ways to relate with their semiosphere. In the game of chess, there's the retrieving of some thematic roles from the historical/political discourse, roles that are then fixed in pieces to characterize and thematize the execution of the game, increasing its appeal and simplifying its comprehension. In backgammon, otherwise, there is only the presence of the theme of escape that directs the player and explains the game, but nothing else. In mancalas, the tangible connection with the sphere of agriculture shapes the game significantly in the course of time.

These two aspects of games, their compound nature and their relationship with the semiosphere, are just a little part of what a semiotic analysis of games could reveal. Many areas of research, points of view, and kinds of games are still to be taken into consideration. Our analysis, then, is just a starting point, a first step in a region of the wide territories of play that, after all, remain largely unexplored.

\section{References}

Bateson, G., (1956). The message 'This is play'. In Group processes: Transactions of the second conference, ed. by B. Schaffner, 145-242. New York: Josiah Macy, Jr. Foundation.

Barthes, R., (1973). Le plaisir du texte. Paris: Seuil.

Carse, J. P., (1987). Finite and Infinite Games. New York: Ballantine Books.

Caillois, R., (1967). Les Jeux et les Homes. Paris: Gallimard.

Compagno D. and P. Coppock (eds.)(2009). Computer games between text and practice. E/C Monografici No. 5. Palermo: Associazione Italiana di Studi Semiotici.

Ferri, G., Haahr, M., Koenitz, H., \& Sezen T. I., (2013). First Steps Towards a Unified Theory for Interactive Digital Narrative, in Transactions on Edutainment X Lecture Notes in Computer Science, Volume 7775, 20-35.

Génette, G., (1982). Palimpsestes - La littérature au second degré. Paris: Seuil.

Greimas, A.J., (1966). Sémantique structurale: recherche de méthode. Paris: Larousse.

Huizinga, J., (1939). Homo Ludens. Leipzig: Academische Verlagsanstalt.

Juul, J., (2005). Half Real. Video Games between Real Rules and Fictional Worlds. Cambridge: MIT Press.

Lotman, J., (1984). O Semiosfere. Trudy po znakovym sistemam vol. 17, 5-23.

Mäyrä F., (2008) An Introduction to Game Studies - Games in culture. London: Sage.

Ortoleva, P., (2012). Dal sesso al gioco. Un'ossessione per il XXI secolo? Torino: Espress Edizioni.

Thibault, M., (2015) Semiotics and Cartomancy: Tartu-Moscow Semiotic School Legacy. KOME - An International Journal of Pure Communication Inquiry 3(2), 19. $\underline{\text { CrossRef }}$ 